\title{
JOSÉ SANTUGINI: EL HUMORISTA SEDUCIDO POR LA SEÑORITA CINEMATOGRAFÍA
}

\author{
Santiago Agullar Alvear
}

Antes de que Perico Chicote abriera su bar americano en la Gran Vía, había ya un lugar donde uno podía codearse con la crema de la intelectualidad sin salir de casa: el epílogo a la novela El hombre de los medios abrazos. Como asistentes al ideal banquete de bodas de los protagonistas, Samuel Ros concita a todos cuantos son en el mundo cultural madrileño en el año 1932. Entre la extensísima nómina de invitados aparece Santugini. Así, sin nombre. También lo menciona Enrique Jardiel Poncela como miembro preeminente de la tertulia del Café Europeo en el prólogo a la primera edición de Amor se escribe con hache, su primera y exitosa novela, aparecida en 1929 en la colección de Grandes Novelas Humorísticas de Biblioteca Nueva.

Tiene esta facilidad Santugini para colar su apellido sonoro en un catálogo y, no obstante, es uno de los humoristas más desconocidos de la generación que surgió de las páginas de Buen Humor. Su prestigio-que lo tiene como guionista- proviene de su asociación con el director húngaro afincado en España, Ladislao Vajda, para el que escribió siete películas, la mayoría de ellas en el seno de la productora Chamartín durante la década de los cincuenta. Hitos como Carne de horca/Il terrore dell'Andalusia (1953), que confronta la imaginería popular del bandolero con la crueldad de sus acciones al servicio de los terratenientes o Mi tio Jacinto/Pepote (1956), que parte del melodrama con niño para colar de rondón una tragedia grotesca sobre la lucha por la dignidad de un torero venido a menos. 
En su condición de escritor cinematográfico Satugini tocó en su periodo de esplendor casi todos los palos. Coadyuvó a la invención del policiaco a la española como argumentista de Brigada criminal (1950), de Ignacio F. Iquino. Para Vajda desarrolló la idea de varias historias entrelazadas cuyo único nexo es su coincidencia en la Séptima página (1951) de un periódico y realizó, junto a José Luis Colina, la excepcional adaptación de la zarzuela Doña Francisquita (1952), conservando la partitura original pero proponiendo un juego de cajas chinas en el que los actores están preparando una representación de la obra lírica al tiempo que viven situaciones que sirven de comentario o contrapunto a las planteadas en el libreto de Federico Romero y Guillermo Fernández Shaw. Participó en las incipientes coproducciones -El deseo y el amor/Le désir et l'amour (1953)-y puso su oficio al servicio de estrellas de ambos lados del Atlántico en títulos como El seductor de Granada (1953), con Luis Sandrini, Congreso en Sevilla (1955), con Carmen Sevilla, S.O.S., abuelita (1959), con Paquita Rico.

Esta es su cara más conocida y la que suele trascender cuando se escriben unas líneas sobre su trabajo o en las necrologías que lloraron su prematura muerte -como si la muerte no fuera siempre prematura- en Madrid, el 11 de abril de 1958. Sin embargo, su ingente labor como humorista emboscado a lo largo de cinco lustros merece algo más de atención.

Se apellidaba Santugini Parada y sus noventa kilos le valieron el diminutivo de Pepe. Nació en Toledo, el 12 de septiembre de 1903. Es contemporáneo por tanto de dos ilustres «del otro 27»: Enrique Jardiel Poncela y José López Rubio, con los que coincidió en las aulas de la facultad de Derecho en la calle de San Bernardo. Antes había estudiado el bachillerato en Málaga. Dice la leyenda que allí publicó con trece años Las coplas de mi alegre guitarra y que fue un relato titulado «El tibor chino», premiado en un concurso del diario primorriverista La Nación, el que decidió su vocación literaria. No puedo confirmarlo porque no he logrado dar con él, pero a partir de aquí dejamos atrás los mitos y nos centramos en hechos contrastados...

Como que a principios de los años veinte del siglo pasado Santugini, cumpliendo los deseos paternos, se instala en Madrid para estudiar Derecho. En esta época hay tertulia juvenil en el Café Europeo de la Glorieta de Bilbao. El estudiante Santugini se escapa allí en cuanto puede para reunirse con un grupo de jóvenes inquietos entre los que descuella la breve figura de Enrique Jardiel Poncela, a quien recurro (Jardiel Poncela [1929] 1999) para censar a los contertulios: Fernando Perdiguero «Menda», Antonio de Lara «Tono», los hermanos López Rubio -Paco, el dibujante, y Pepe, el incipiente comediógrafo-, los hermanos Mihura-Miguel, el 
pequeño, también dibujante y humorista embrionario, y el mayor Jerónimo, empleado de correos y envenenado del cine, como lo están Antonio Barbero y Carlos Fernández Cuenca-. Buena parte de ellos aparecen en la plantilla de Buen Humor, primer órgano del «humor nuevo». En el número del 8 de junio de 1924 ve la luz «La corona», el primer relato de Santugini en la revista donde se encuentran la totalidad de los que José López Rubio -redactor-jefe de la publicación por aquel entonces - bautizaría andando el siglo como «la otra generación del 27》. Con todos ellos comparte Santugini mundo y estilo.

Su iconografía personal se nutre del más allá -aparecidos, espiritistas, fantasmas que se asustan de los mortales-, vendedores de felicidad, antropófagos satisfechos, «ratas» de hotel o ferrocarril embutidos en monos negros «a lo Fantômas» y robinsones que, ya en su vejez, no saben recibir a las visitas. A menudo estos personajes se ven envueltos en dramas grotescos o paradójicos: el náufrago no desea volver a la civilización; el duelista contumaz, ante la incomparecencia del contrario, dispara contra sí mismo; el hombre aprisionado en la puerta giratoria de un café, que aguarda su trágico final. En su apunte biográfico Gómez Tello afirma: «Sus cuentos son un espejo cóncavo de la vida, de la honesta, burguesa y limpia vida» (Gómez Tello 1946). Echemos un vistazo al espejo cóncavo...

Él mismo tiene la cortesía de presentarnos a su musa: «Adelaida es alta, gruesa, morena y un poquitín bizca; bajo la nariz, graciosamente respingona, florece una suave pelusilla que le presta cierto aire marcial; tiene una mancha en el carrillo izquierdo, que ella denomina antojo, y tres dientes de oro, que muestra continuamente» (Santugini 1931a). La verdad es que le suministra pocos temas porque, cuando Santugini recurre a ella, vuelve sobre los que acabamos de citar.

Careciendo de información de primera mano arriesgo aquí una terna de modelos: Wenceslao Fernández Flórez, Massimo Bontempelli y Mark Twain. Como ellos es Santugini un humorista preciso. Suele atacar el relato en mitad del conflicto, define a los personajes con agilidad de caricaturista y luego escribe con trazo firme, hasta el efecto final. Muchos cuentos están divididos en escenas que cierra con un efecto de telón; luego, una elipsis de neta estirpe cinematográfica. Están escritos generalmente en primera persona, poniendo a prueba la credulidad del lector al que el escritor suele interpelar. Su temática puede discurrir por cauces cotidianos llevados ad absurdum o entrar de lleno en el terreno de lo fantástico. «Ultratúmbico» es uno de los adjetivos que suelen repetirse. Veamos un ejemplo.

«Un alma grande» pone en escena la historia trágica de Víctor Camiel, que de resultas de un atropello -el automóvil, el automóvil humanizado tantas veces, otro tema recurrente en los humoristas del periodo-re- 
sulta ileso pero pierde su alma. La única manera de hacerse con una y no andar por ahí demediado es robarla y él se decide por la de una señora gruesa cuya alma se le antoja plena de felicidad. Sin embargo, ahora Víctor tropieza con todo. «iEl alma nueva, que le estaba grande y que se le enredaba en los pies! Tuvo que inclinarse, recoger con ambas manos la parte del alma molesta y echársela sobre los hombros, embozarse con ella como si fuera una capa» (Santugini 1926a).

La mujer contemporánea -sintetizada en el «Autorretrato» de Tamara de Lempicka al volante de un Bugatti y la popularización que de esta imagen hicieron Penagos y otros ilustradores de Blanco y Negro- es el modelo de la protagonista del apólogo titulado «De cómo estuve a punto de ser raptado» (Santugini 1928). La incongruencia nace en este caso de la imagen que la familia tradicional tiene de la mujer automovilista. Entre todos $-\ll$ mi padre, mi madre, mi hermana la casada y mi hermana la soltera»-alientan la paranoia del protagonista que termina por sucumbir a la presión familiar:

${ }_{-¡}$ Oh, no me mires! ¡Y no me toques! ¡Eres una mujer fatal!... [...] ¡Estoy enterado de todo! ¡Sé que has envenenado a un príncipe ruso, que has hecho saltar varias veces la banca del casino de Montecarlo, que has arruinado a un multimillonario norteamericano y que has hecho morir de celos y de amor a un estudiante húngaro! ¡Pero a mí no me engañarás! ¡O paras, o me arrojo en marcha!...

Comenzó a reír.

- ¡Ahora comprendo el terror de mi familia! ¡No te rías, no! ¡Vuelve! [.... Al descender yo del automóvil, la boca de la mujer fatal se frunció en un gesto irónico.

Ya en casa, algo más tranquilo, fingí una sonrisa y dije:

- ¿Lo veis como vuestros temores eran ridículos?

Y principié a cenar, baja la cabeza y fija la mirada en el cubierto.

Otro automóvil había protagonizado un relato anterior (Santugini 1926b). Entonces fue la obsesión del protagonista al tomar un taxi junto a su prometida y empezar a calcular cuánto les costaría su vida en común a veinte céntimos cada tanto -idea, ésta, del vértigo existencial pautado por las frías e inexorables maquinarias que rigen nuestras vidas, que desarrollaría con mayor profundidad Francisco de Cossío en su novela Taxímetro (1940)-. En Santugini todo se resuelve fulminantemente. El narrador enloquece y está a punto de asesinar a su prometida a la que abandona a la puerta de su casa para no volver a verla jamás... Ni a coger tampoco un taxi, por supuesto.

En el último número de Buen Humor publica «El centenario». El abuelo de la familia Gómez y Gómez comienza a sentirse rejuvenecido, 
pero no como en Cuatro corazones con freno y marcha atrás por el elixir de la juventud a base de «extracto de alga frigidaris» del doctor Bremón, sino por el simple hecho de recibir un poco de cariño y atención de su familia. La inversión del crecimiento adquiere tales proporciones que el abuelo «fue, progresiva y rápidamente, disminuyendo de estatura, infantilizándose, hasta que un día murió en los brazos de mi madre, bajo la mirada del doctor, que había pronosticado a aquella dentición penosísima un trágico desenlace» (Santugini 1931b).

El semanario rinde viaje a finales de 1931, recién estrenada la República, después de diez años de renovación y con una feroz competencia en el campo de la prensa humorística. Desde junio de 1924, Santugini ha publicado casi un centenar de colaboraciones y, sobre todo, se ha hecho escritor. Escritor de «buen humor». Humorista.

¿Ha habido una crisis en 1927? Lo ignoro. La cosa es que el resto de los jóvenes valores se han ido en pos de Ricardo García, $K$-Hito, a la flamante Gutiérrez, financiada por el ingeniero, empresario y editor Luis Montiel. Los más ambiciosos ramilletean sus relatos perdidos en las efímeras páginas de la prensa en forma de libro: los Cuentos inverosímiles de López Rubio salen en Caro Raggio en 1924 y Edgar Neville publica en 1926 la colección de narraciones Eva y Adán en la imprenta que los poetas Altolaguirre y Prados tienen en Málaga.

Santugini ha permanecido fiel a Buen Humor y al formato de colaboración semanal, aunque su firma empieza también a cotizarse en las principales revistas del momento: Estampa -también propiedad de Montiel-, Blanco y Negro y su suplemento infantil, Gente Menuda. Además, participa en otra revista para niños de corta trayectoria pero hondo calado, dirigida por Antoniorrobles: El perro, el ratón y el gato.

Mientras, ha habido un cambio radical en su vida: ha caído en brazos de la cinematografía. No sólo es un aficionado impenitente sino que entra a trabajar en funciones de director artístico en la Sociedad Anónima General de Espectáculos, la compañía de los arquitectos Saturnino Ulargui y Secundino Zuazo. La revista Primer Plano resumirá así su trayectoria en la compañía: «...defendió $Y$ el mundo marcha-sin equivocarse en su valor- y trajo a España las primeras de Boris Karloff y las primeras habladas de Stan Laurel y Oliver Hardy; trajo Trader Horn y se empeñó en que Luces de Buenos Aires no gustaría, equivocándose» (Gómez Tello 1946). En 1926, la SAGE construye el cine Palacio de la Música, una de las primeras salas en instalar equipo para la proyección de cine sonoro. Santugini figura como «representante» de la misma en el Anuario Cinematográfico Español de 1935. De esta época proviene su jactancia de haber sido el 
único hombre que ha visto morir a un espectador de cine en un estreno de Joan Crawford.

$\mathrm{Su}$ afición al cine le empuja a escribir sobre el medio, primero en Crónica -a partir del nº 3 (1-XII-1929) hasta junio de 1930-, luego en Cinegramas, desde su salida en el verano de 1934. En ambos casos alterna sus cuentos con gacetillas humoristicas sobre los usos y costumbres de las estrellas y los directores de Hollywood, agrupadas en la serie «Mitad en broma, mitad en serio». En ellas recurre con frecuencia a la greguería: «La Pandilla, Baby LeRoy, Shirley Temple, Spanky y otras estrellas infantiles constituyen la Vía Láctea del firmamento cinematográfico») (Santugini 1934b).

Con todo, la serie de más largo recorrido son sus «Complementos Cortos», en cinco entregas dobles, que constituyen retratos al minuto de figuras del mundo del celuloide como el chucho de la película, el comparsa o el director.

Este último es un tiránico realizador germánico que casca de un berrinche tras destrozar con sus propias manos un decorado a escala natural de la Muralla China (Santugini 1935c):

Murió tan de improviso, que ni él mismo pudo darse cuenta de que se había muerto hasta que se halló bajo una luz potente, superior a la de los focos de los Estudios, rodeado de montañas de una transparencia blanquecina, sonrosada y áurea.

El director arrugó el entrecejo y gritó:

-iMenos luz! ¡iMenos!!

Después, entre el asombro de los que acudían a sus voces, fue dando órdenes incomprensibles para todos:

-¿Quién es el escenógrafo de esto? ¡Que venga inmediatamente! $\mathrm{O}$, mejor, ¡que lo despidan! ¡Así no se puede trabajar!

El humor deshumanizado asoma también en la viñeta del niño actor que, ante la muerte de su padre, necesita de la presencia del director que es el único capaz de arrancarle una emoción plausible. $O$ en la del doble de acción, que con la llegada del sonoro y el diluvio de operetas filmadas tiene que arreglárselas para sobrevivir: «Hubiera muerto de hambre de no habérsele ocurrido la idea salvadora. Y hoy el doble sustituye en el momento preciso al señor que necesita extraerse una muela, al esposo que regresa tarde a su casa, o al enfermo que ha de someterse a una operación quirúrgica. Lo sustituye, sí. En lugar del cliente, el doble se deja extraer la muela, recibe la paliza de la indignada esposa o sufre la operación. Por este procedimiento tan sencillo ha ganado cerca de millón y medio de dólares» (Santugini 1934a). 
Sus colaboraciones no alcanzan la treintena pero es que durante la segunda mitad de 1935 está inmerso en el rodaje de su única película como director: Una mujer en peligro (1936). La produce la Atlántic Films y la protagoniza Antoñita Colomé, compañía y actriz con las que otro compañero de redacción en Buen Humor, Edgar Neville, rodará poco después La señorita de Trevélez (1936), en la que, a su vez, Santugini aparecerá brevísimamente interpretando a un expendedor de billetes de autobús.

Para escribir el guión de Una mujer en peligro, Santugini cuenta con la inestimable ayuda de su antiguo compañero de tertulia en el Europeo, Carlos Fernández Cuenca, con mucha más experiencia que él en este campo, pues ya se ha fogueado como director y ha publicado varias monografías de teoría e historia cinematográfica. El resultado de sus esfuerzos conjuntos es la historia de Fernando Herrero (Enrique del Campo), un crápula millonario que, atormentado por su conciencia, decide suicidarse. No es el individuo acorralado por la vida de El hombre que se quiso matar; su tipo de suicida está más cercano al Mario Esfarcies de iEspérame en Siberia, vida mia!, que recurre a los servicios de la Unión General de Asesinos sin Trabajo. En este caso, Fernando acude al doctor Arnal, adalid del «asesinato científico para el estudio del cerebro humano». Con las horas contadas, la vida de Fernando dará un vuelco al recibir la llamada de Isabel, «una mujer en peligro». Acudirá en su rescate a un caserón siniestro donde los cadáveres desaparecidos y los aparecidos sin filiación sirven de acicate para su amor. Al final del plazo él no tiene el más mínimo interés en abandonar este mundo, pero ha de reconocer que «un suicida que no quiere morir es un ser tan extraordinario como ridículo». El doctor Arnal le explica entonces que todo ha sido una farsa que ha montado, aprovechando que había comprado el caserón para instalar allí una clínica. Los siniestros personajes son sus ayudantes. El fingido parricida es un pobre cómico en paro... al que olvidan en la prisión como risueño contrapunto al final feliz de Fernando, quien termina confesando a Isabel que «si todo hubiera sido verdad y yo la hubiese salvado me habría tenido que casar con usted... Pero como es usted la que me ha salvado a mí, es usted la que se tiene que casar conmigo».

Santugini define la historia como «una farsa de humor y de intriga, con cierta originalidad en su desarrollo» (Hernández Girbal 1935). Los compañeros de redacción de Cinegramas alaban su trabajo: «En su primera película -asunto, diálogo y dirección suyo- demuestra originalidad, humor, buen gusto y un agudo sentido de la técnica cinematográfica» (Guzmán Merino 1936). Desde una sensibilidad más contemporánea argumenta Román Gubern que la película «demostraba una muy hábil asimilación de la comedia de misterio formalizada a finales del mudo 
por el alemán Paul Leni en Hollywood. [...] Y era una prueba contundente del buen nivel técnico y profesional y de la exportabilidad del cine español realizado con responsabilidad industrial») (Gubern 1977).

La película se estrena poco antes de la sublevación militar del 36 y tan prometedor debut no tiene continuidad. El rastro de Santugini desaparece durante la guerra, al menos en lo que se refiere a trabajos cinematográficos. En 1938, en la Barcelona pendiente del frente del Ebro, se presenta con discreto resultado la zarzuela de ambiente huertano El ramo de la Fuensanta, música de Juan Dotras Vila y libreto de Santugini en colaboración con otro compañero de generación, el primer cómplice de Jardiel, Serafín Adame. Los historiadores del género la tildan de «escapista», pero probablemente el ambiente no era para menos.

Su labor literaria tiene continuidad en 1940 en el semanario Tajo, donde se codea con la plana mayor de los literatos falangistas, como Samuel Ros, Rafael Sánchez Mazas o Dionisio Ridruejo. En la revista hay dos páginas de humor que aún llevan la cabecera de La Ametralladora y van firmadas al alimón por Mihura, Tono y Jacinto Miquelarena. Sobre cine escribe Rafael Gil. La colaboración de Santugini en el primer número lleva por título «El silencio» (Santugini 1940) y tiene un tono más sombrío que las prebélicas, o al menos así se me antoja. Un hombre acosado por el remordimiento de un crimen impreciso e inconfesable se ve agobiado por el silencio que «ataca al hombre, lo envuelve, lo aísla y se adentra en su cerebro para enloquecerle o matarle». Probablemente intentar descubrir aquí la metáfora de la España posbélica sería buscarle tres pies al gato; de lo que no cabe duda es de que el ambiente no es propicio para la escritura festiva. Habrá que esperar todavía un año, hasta junio de 1941, para que la aparición de La Codorniz llene el silencio de risas cómplices. Una vez más, Santugini permanecerá aparte del grupo formado por Mihura, Tono, Neville y Herreros, bien que luego acuda de tarde en tarde a la tertulia que mantienen en Chicote.

Por las mismas fechas Santugini intenta el asalto a los escenarios en solitario. Josefina Díaz y Manuel Collado le estrenan Una carta de amor; en 1942 se pone en escena Te debo la vida y diez años más tarde se estrena su versión de la comedia de Henry Crozier Los siete besos del camarero. Si Te debo la vida está hecha a la medida del cómico Pepe Alfayate, la comedia de Crozier se adaptada al personal acento de la actriz húngara Lilí Murati.

¿Comicidad teatral? Sin duda. ¿Teatro de humor? Probablemente nada más lejos de la intención de Santugini. Las tres comedias que llevan su firma parecen cortadas por el mismo patrón: intrigas certeras, manejo ágil de situaciones estándar y un diálogo chispeante que lleva al especta- 
dor en volandas hacia un final no menos feliz. Estamos tan lejos del modelo jardielesco de inverosimilitud a prueba de bomba como del descoyuntamiento del lenguaje que es marca de la casa en las funciones de Tono.

En el terreno estrictamente cinematográfico, durante los años cuarenta Santugini sólo logra colocar tres guiones. En el número 9 de la revista Cámara (1942) se da la noticia de que va a proporcionar un libreto a $\mathrm{Ra}-$ fael Gil titulado « ¿Usted se casa conmigo!». El guión todavía ronda por las productoras en 1948, cuando Hidalguía Films lo anuncia entre sus proyectos para Juan de Orduña. El dibujante Enrique Herreros tiene en cartera el guión de «Loco por ti» y el periodista José G. Ubieta prepara su debut en la realización de largometrajes con «Detrás de una mujer». Ninguna de las tres películas llega a realizarse.

Aparte del crédito surreal como «asesor literario» de Manuel Villegas López en el guión de La guitarra de Gardel (1949), el balance creativo de Santugini en esta década se reduce a un guión original y dos adaptaciones, en las cuales, no obstante, se puede apreciar una razonable continuidad con sus planteamientos anteriores a la Guerra Civil. Al fin y al cabo, los cultivadores de la comedia cinematográfica adscritos al bando de los vencedores no tienen otros modelos. Jardiel Poncela, Fernández Flórez o Pedro Muñoz Seca -por citar tres ejemplos variopintos- seguirán siendo referentes literarios.

Viaje sin destino (1942), que dirige Rafael Gil, revisita el decorado de Una mujer en peligro: el siniestro caserón poblado de personajes que son «un remedio contra el hipo».

Federico Poveda (Antonio Casal), aficionado a las novelas policíacas y empleado de la agencia de viajes Panorama, organiza los «Viajes sin destino» del título, que conducen a un grupo heterogéneo al hotel $\mathrm{La}$ Luna Rosa cuyo propietario es un pobre viejo desquiciado. Don Daniel Gavirza (como siempre genial Alberto Romea) les cuenta a sus inesperados huéspedes la causa del abandono del lugar: la rivalidad amorosa con su hijo empujó a éste al suicidio. Desde entonces el espectro vaga por el caserón. Fantasmas, hombres invisibles y cadáveres que se esfuman en habitaciones cerradas mueven, una vez más, el romance de Poveda con la campeona de natación Rosario (Luchy Soto).

La heterogénea filiación de la película pasa de la modalidad romántica al slapstick y la comedia social al gusto de Capra, deriva hacia la humorada de trucos y fantasmagorías, inserta un «celuloide rancio» y finaliza con una persecución a tiros en toda regla con llegada de la policía en el último instante incluida. Seguramente es esta mezcla indiscriminada de registros lo que echaba para atrás a los realizadores y productores a los que Santugini les presentaba el proyecto: «El pretexto era que la gente 
no iba a comprenderlo, porque se rompía una línea clásica de modo de cine. Justamente lo que yo pretendía hacer. Justamente lo que creo que se debe hacer siempre que se pueda, porque el cine tiene un rostro múltiple» (Santugini 1944).

En los comentarios contemporáneos Viaje sin destino suele quedar emparedada en el díptico de inspiración fernandezfloreciana constituido por el brillante debut de Gil con El hombre que se quiso matar (1942) y su primer éxito resonante, Huella de luz (1942). Félix Fanés, por ejemplo, afirma sin ambages que pasado el primer rollo la película se pierde en «una barreja de gèreneres desproveída de picardia y habilitat» (Fanés 1989). El cronista de Cifesa apunta como signo del poco aprecio que el propio director pudiera sentir por esta película el hecho de que en la siguiente, su muy poco jardielesca adaptación de la jardelianísima Eloísa está debajo de un almendro (1943), se proyecte Viaje sin destino y un espectador se ponga a roncar. Quien quiera ver la película con menos prejuicios apreciará que el asunto no pasa de ser una parodia autorreferencial tan común al género, por no mencionar que el vecino roncador se ha quedado sobado durante la proyección del No-Do y no en la de Viaje sin destino, durante la cual, además, reconviene a las damas por no dejar de parlotear. Es más, la tía Clotilde menciona varias veces el hecho de que esta película le recuerda a la casa de Bernardo y Ezequiel, con la contingencia de que cuando habla de este último, encarnado por Alberto Romea, aparece en pantalla el Alberto Romea que encarnara a Gavirza. Juego de espejos enfrentados utilizado por Gil con inteligencia; nunca comentario despectivo de su anterior película.

El siguiente guión de Santugini que llega a la pantalla bajo la ágil dirección de Ladislao Vajda es la adaptación de la novela de María Luisa Linares, Doce lunas de miel (1943). Santugini resumía de este modo sus iniciales desavenencias con el director húngaro: «Yo he tenido grandes discusiones con Vajda. Vajda, como director - y yo no se lo discuto- gusta del matiz. Él entendía que bastaba con arrancar al público una sonrisa. Yo, como guionista, opinaba que en la oscuridad de la sala es muy difícil hacer una estadística de las sonrisas. Y muy fácil registrar las carcajadas» (Santugini 1944).

La señora viuda de Torres de Montalvo y Ortiz, que ha sido tremendamente feliz en sus tres matrimonios -itres!-, decide dotar a doce parejas seleccionadas. Los interesados realizan un concurso de méritos que les hará merecedores de las tantas mil pesetas de la época. Un inventor en busca de inversor (Antonio Casal) y una aspirante a actriz (la portuguesa Milú) se ponen de acuerdo para fingir un noviazgo que les permita disponer del dinero para sus fines. Como en tantas historias de este tipo, el matrimonio no se consumará hasta que los contrayentes encuentren verdaderamente el amor después de equívocos y malentendidos sin fin. 
De los problemas que supone la adaptación de un material preexistente afirma Santugini: «Salvemos el guión técnico, que debe hacerlo el director. Pero el argumentista, el guionista y el autor de los diálogos deben ser el mismo. Ya está dicho mi criterio sobre la adaptación de la novela, donde el autor impone su argumento, y la adaptación de teatro, donde el autor obliga a incrustar en la película largos trozos anticinematográficos»» (Santugini 1944).

La revisión a que somete Santugini el texto de María Luisa Linares es total. En una de las primeras escenas aprovecha para caricaturizar de un plumazo el carácter endeble del sagrado vínculo que la película se ve obligada a ensalzar en razón de la época y la censura. Una pareja talludita explica su situación a la benefactora:

LEONCIA: No tenemos dinero y estamos enamorados. ¿Tenemos dinero?

FAUSTINO: No.

LEONCIA: ¿Estamos enamorados?

FAUSTINO: ...

LEONCIA: ¿Eh? ¡Contesta! (FAUSTINO se encoge de hombros.)

«Yo he tenido grandes discusiones con Vajda. Vajda, como director -y yo no se lo discuto- gusta del matiz. Él entendía que bastaba con arrancar al público una sonrisa. Yo, como guionista, opinaba que en la oscuridad de la sala es muy difícil hacer una estadística de las sonrisas. Y muy fácil registrar las carcajadas. Cada carcajada, mil pesetas en taquilla. Logré que se pusiera aquel chiste de Lérida que tú conoces» (Santugini 1944). El chiste de Lérida consiste en que, durante el banquete, para aparentar una animada conversación, él recita una lección de geografía política sobre dicha provincia en tono amoroso. Concluye:

JAIME: Se lo juro, Julieta.

JULIETA: Lo creo, Jaime. El corazón me dice que usted no me engaña. JAIME: No puedo engañarla. Hice oposiciones a Correos, pero no saqué la plaza.

JULIETA: Fue una injusticia.

JAIME: Ahora voy a decirle algo más difícil. Voy a decirle los pueblos que tiene Badajoz: Almendralejo, Castueña, Don Benito...

Cuando va por Villanueva de la Serena, doña Flora les emplaza en su finca al cabo de tres años en los que el argumento se ocupará de acumular obstáculos para una unión final perfectamente previsible. 
Concluyo este repaso a los proyectos cuajados con una de las películas más apabullantes no sólo del cine español de los años cuarenta, sino de la comedia de raíz fantástica de cualquier tiempo y ámbito: La torre de los siete jorobados (1944). En otro lugar (Aguilar 2003) he intentado desentrañar la auténtica paternidad de esta película, la incorporación de última hora de su viejo amigo Edgar Neville al proyecto y su origen en una entrevista que Santugini realizó al novelista Emilio Carrère en 1935 para Cinegramas (Santugini 1935b).

Los méritos de la adaptación estriban en el soberbio trabajo de acoplamiento genérico entre los elementos sainetescos de la trama y la iconografía fantástica. Alfredo Marqueríe afea la conducta a los autores desde su tribuna en La Codorniz (Marqueríe 1944):

$¡$ Hombre! A esto no hay derecho. De modo que nos pasamos la vida diciendo que nuestro cine es malo, que vivimos de la imitación del extranjero, que nuestros argumentistas, nuestros guionistas, nuestros directores, no tienen imaginación para elevar los temas a categoría fantástica y, de pronto, José Santugini y Edgar Neville se ponen de acuerdo para dejarnos mal. [...] Pero si resulta que estos directores y estos guionistas, como Neville y Santugini, empiezan a rodar películas originales, interesantes y graciosas, tendremos que ir pensando en que existe una confabulación contra nosotros para dejarnos en ridículo. Porque ya comprenderán que para hacer elogios están los anuncios.

No todos lo ven así. Los cuarenta son malos tiempos para la comedia $y$, por ende, malos para Santugini; años difíciles, pero también aquellos en que él saca mejor partido de su fantasía abocada a la comedia sin ambages. Los tres antihéroes a los que Antonio Casal presta su máscara han ganado en humanidad sin abandonar sus rasgos esenciales trazados en los años de Buen Humor: tipos atrapados entre la realidad y el deseo con un pie en el más allá y el otro en un más acá necesitado de fantasía.

El resto es historia. Al menos, la modesta historia cinematográfica española. Ya consagrado, se queja del poco reconocimiento que sigue teniendo el oficio de guionista. «El que se nos conozca algo más se lo debemos al cine italiano porque con las películas de Vittorio de Sica se comienza a hablar de un guionista, Zavattini, casi tanto como del director» (Barreira 1956). Del guión que se siente más satisfecho es del de Carne de horca, en el cual no hay demasiado humor. El que le gustaría hacer: «Uno que sirviera para una película muy humana, tratada con un humor que no excluyera el toque dramático». 
¿Sería éste «Historia de una nación»? Se trata de una sinopsis de cuatro páginas conservada en la sala de manuscritos de la Biblioteca Nacional (Santugini 1954), gracias a la cual tenemos ocasión de asomarnos al Santugini embrionario. Aquí se nos ofrece la historia urdida por él desnuda de carne, al aire sus huesos mondos, sin la mediación técnica de Vajda, Gil o Neville.

«La acción transcurre en las proximidades del año 2000 en una nación indeterminada o simplemente imaginaria». No hay más remedio que empezar por aquí, porque una vez más la historia situada en el futuro nos remite al pasado reciente $y$, peor aún en el caso de una comedia, a nuestro pasado bélico y cinematográfico.

Érase, pues, que se era un país en el que la cartera más importante es la de Propaganda. Al poder de este omnímodo ministerio se someten todos los demás. El Ministro recibe al Primer Productor de la nación. Por la época en que se escribe podemos imaginarlo con los rasgos de Cesáreo González, aupado sobre las ruinas de Cifesa y en un pulso permanente con la administración entre lo exportable y lo mostrable. Los aires cambiantes de la política cinematográfica del régimen se exponen sin afeites, porque en tanto el productor intenta venderle al Ministro un nuevo vehículo de propaganda ideológica, éste aboga por la pura y simple diversión: películas como Scaramouche o Los tres mosqueteros. Cuando el productor arguye que de la novela de Dumas ya se han hecho veintidós versiones, el Ministro responde que la vigésimo tercera será la mejor de cuantas se hayan realizado. Para ello pone a su disposición todos los medios del país.

El productor, émulo de Borges, concibe un decorado que sea el París del siglo XVII -precisando, eso sí, que se construirá sobre las ruinas de una ciudad asolada por la última guerra-. Adiós al cartón piedra. La corte de Luis XIII será real, no fingida. Bastará para ello reconstruir la ciudad y poner allí a vivir a un puñado de miles de habitantes. Entra entonces en juego el director, que supervisa toda la operación y concibe un reparto en el que sólo hay un profesional. El legado neorrealista ha hecho mella en la nación y para encarnar a D'Artagnan se localiza a un muchacho que apenas ha salido de un pueblecito montañés al que no ha llegado la civilización.

Ya había explorado con anterioridad Santugini las posibilidades cómicas de esta situación en «El mejor film de gángsters» (Santugini 1935a), donde aparecía un director tan apegado al realismo que cuando tiene que hacer una película de gángsteres recluta a verdaderos pandilleros. La escena cumbre es un tiroteo entre criminales y policías. Cuando termina la toma, todos han muerto. El director echa la bronca a su asistente, pero él no tiene la culpa de nada: los gángsteres han muerto de miedo, «ante el tremendo verismo de la escena». 
En «Historia de una nación» también los nobles son auténticos aristócratas y los más diversos oficios son vividos antes que interpretados por artesanos de cada especialidad. No hay ensayos, pero si un largo periodo de convivencia en que todos se acostumbran a esta vida. El único profesional es contratado para encarnar a un mendigo, lo que más adelante tendrá consecuencias en el curso de la acción.

La única tecnología que entra en la ciudad son los equipos cinematográficos, pero... Cuando se está dando la primera vuelta de manivela irrumpe en el encuadre el coche del productor. El director lo maldice. El motivo del productor no es baladí. Acaba de estallar una nueva guerra. Reunión en el salón del trono. El director no está dispuesto a renunciar a su película y la ciudad es autosuficiente gracias a la autarquía. En la capital se anuncia la deserción en masa del equipo de la película y se envían policías armados para reducirlos. Quinientos mosqueteros se aprestan a la defensa pero en un alarde potemkinesco los policías enviados a sofocar la rebelión se unen a los insurrectos. ¿Por qué dejarse matar en una nueva guerra?

Deciden vivir en la ciudad a la espera de que se abran de nuevo los laboratorios y poder seguir con el rodaje. Cada uno hará entretanto el papel que tiene asignado. Todos se muestran de acuerdo salvo el actor que interpreta al mendigo. Inmediatamente es conducido a la Bastilla. Ahora no le falta nada a la nación: ya tienen hasta un preso y -más aún- un preso ipolítico!

Sin embargo, pronto se demuestra que el del actor no es un caso aislado. Lo que no puede controlar el director es que cada uno tenga los mismos sentimientos que su personaje: «Milady es una buena chica; el cardenal Richelieu no intriga; Ana de Austria siente una irreprimible antipatía hacia el Duque de Buckingham. [...] Todos quieren vivir sus vidas y rechazan las que Dumas escribió»».

La ciudad es como una nueva Arca de Noé. Los cuatro mosqueteros realizan una batida de reconocimiento. Regresan espantados. Por todas partes hay hambre, miseria y destrucción. La solución: cerrar para siempre las puertas de la ciudad. El director convence entonces a todos de hacer lo contrario. Hay que salir y enseñar al mundo que se puede vivir «sin rencores», cada uno dedicado a su modesta labor cotidiana. La moraleja de la fábula en labios del director: «Será una vida mejor que la de hoy».

¿Consecuencias de la lectura autárquica que la administración ha realizado del éxito de ¡Bienvenido, Mr. Marshall! (1953) en Cannes? ¿Una apuesta por la apertura al exterior? ¿Pacifismo atemporal? La fantasía es lo que tiene, que admite cualquier lectura. 
Fue José Santugini un hombre querido por sus contemporáneos. Enrique Herreros hijo lo recuerda asistiendo a los estrenos con su físico imponente y su mujer menudita con la cara picada de viruelas. Es como en esos dibujos que hacía su padre -el de Herreros- en los que la gente llevaba a hombrecillos metidos en los bolsillos. Herreros cuenta en alguna entrevista -excúsenme citarla porque ahora mismo no tengo la referencia a mano y suficientes he hecho ya a lo largo de este artículo- cómo les gustaba: Santugini sentaba a Herreros sobre sus rodillas y entre ambos improvisaban el número del muñeco del ventrílocuo.

A su muerte Miguel Pérez Ferrero afirma que Santugini es «acaso el mejor guionista cinematográfico que en la actualidad poseía nuestro país», en lo que redunda Méndez Leite cuando subraya entre los hechos reseñables de 1958 el fallecimiento del guionista como la pérdida de «uno de los mejores», con el añadido de que si supo salir indemne de tantos empeños fue «porque conocía como pocos los secretos del arte cinematográfico» (Méndez Leite 1965).

En la esquela que publica $A B C$ al pie de su nombre dice sencillamente: «escritor cinematográfico». 


\section{BIBLIOGRAFÍA:}

Aguilar, Santiago. 2003. Edgar Neville: tres sainetes criminales, Filmoteca Española, Madrid.

Barreira, Domingo. 1956. «Con quince preguntas basta: Contesta José Santugini». Primer Plano, $\mathrm{n}^{\circ} .831,16-\mathrm{IX}-1956$.

FANÉs, Félix. 1989. El cas Cifesa: vint anys de cine espanyol (1932-1951),

Valencia, Filmoteca Generalitat Valenciana.

Garcia Fuentes, Enrique. 1995. Int. a: ROS, Samuel. El hombre de los medios abrazos, Madrid, Biblioteca Nueva.

Garcia Viñolas, Pío. 1958. «Ha muerto José Santugini», Primer Plano, $\mathrm{n}^{\circ} .914,20-\mathrm{IV}-1958$.

Gómez Tello, José Luis. 1946. «Quién es quién en la pantalla nacional:

José Santugini», Primer Plano, nº 307, 1-IX-1946.

Gubern, Román. 1977. El cine sonoro en la II República. 1929-1936. Barcelona, Lumen.

Guzmán Merino, Antonio. 1936. «La semana cinematográfica», Cinegramas, $\mathrm{n}^{\circ} .78,8-\mathrm{III}-1936$.

Heredero, Carlos F. 1993. Las huellas del tiempo: Cine español 19511960. Filmoteca Española / Filmoteca de la Generalitat Valenciana.

HeRnáNDEZ GiRBAL, Florentino. 1935. «Viendo rodar una película», Cinegramas, $\mathrm{n}^{\circ}$ 57, 13-X-1935.

Jardiel Poncela, Enrique. [1929] 1999. Amor se escribe sin hache, ed. de Roberto Pérez, Madrid, Cátedra.

LlıNÁs, Francisco. 1998. Ladislao Vajda: el húngaro errante, Valladolid, Seminci.

MArquerí, Alfredo «El espectador Marqueríe». 1944. «El cine desde la butaca», La Codorniz, n 175, 10-XII-1944.

MÉndez-Leite, Fernando. 1965. Historia del cine español, Madrid, Rialp.

Pérez Ferrero, Miguel «Donald». 1958. $A B C, 12-\mathrm{IV}-1958$.

RIAmbau, Esteve y TORREIRO, Casimiro. Guionistas en el cine español:

Quimeras, picarescas y pluriempleo, Madrid, Cátedra / Filmoteca Española, 1998.

Ródenas, Miguel. 1942. «Informaciones teatrales: Estreno en el Reina Victoria de Una carta de amorn, ABC, 6-III-1942.

- 1952. «Estreno en el Teatro Cómico de Los siete besos del camarero», Coliseo, $\mathrm{n}^{\circ} 10,31-\mathrm{V}-1952$.

Santugini Parada, José. 1926a. «Un alma grande», Buen Humor, n²32, 9-V-1926.

- 1926b. «El suplicio», Buen Humor, n² 234, 23-V-1926. 
- 1928. «De cómo estuve a punto de ser raptado», Buen Humor, n ${ }^{\circ} 345$, 8-VII-1928.

- 1931a. «Adelaida», Buen Humor, no 512, 25-X-1931.

- 1931b. «El centenario», Buen Humor, nº 520, 20-XII-1931.

- 1934a. «Complementos cortos: El mago de la caracterización / El doble», Cinegramas, nº 5, 14-X-1934.

- 1934b. «Mitad en broma, mitad en serio. Comentarios a la salida», Cinegramas, $\mathrm{n}^{\circ}$ 16, 30-XII-1934.

- 1935a. «Complementos cortos: El mejor film de gángsters», Cinegramas, $\mathrm{n}^{\circ} 18,13-\mathrm{I}-1935$.

- 1935b. «Una pregunta a los novelistas: ¿Cuál de sus obras cree Vd. más adaptable al cinematógrafo y por qué?», Cinegramas, $\mathrm{n}^{\circ} 34,5-\mathrm{V}$ 1935.

- 1935c. «Complementos cortos: El director», Cinegramas, $\mathrm{n}^{\circ} 37,26-\mathrm{V}$ 1935.

- 1940. «El silencio», Tajo, no 20, 12-X-1940.

- 1944. «Para ayudar a la luz del alba. Conversaciones con guionistas: José Santugini», Primer Plano, n 172, 30-I-1944.

- 1954. Historia de una nación (sinopsis), Madrid, Imp. Gestetner.

Torruos, José María (ed.). 2003. José López Rubio: la otra generación del 27, Discurso y cartas, Madrid, Centro de Documentación Teatral. 